\author{
Michael Elliott \\ studiomichaelelliott@gmail.com
}

\title{
Artist Statement
}

\section{The "Windrush" Series: Behind the Paintings}

In retrospect, the "Windrush" Series wasn't always something that I intended to do, but more something that came out of the news of the growing Windrush scandal that has gripped Britain, in recent years. I've always been aware of the history of West Indians who migrated to Britain and the social problems that they faced.

However, the Windrush scandal opened my eyes to the magnitude of the problems of their integration. It prompted me, in the summer of 2018, to develop the "Windrush" Series when I was engaged in a residency program in Miami, organized by the Diaspora Vibe Cultural Arts Incubator (DVCAI) and Warehouse 4726.

During the month of July, 2018, I started cultivating ideas and creating pieces based on reports of the Windrush saga. I carefully navigated the history of the Windrush, and learned more about what the immigrants went through in Britain, from their first arrival, after World War II, through to modern times.

For the first painting, in the series that I called: 'Storm in a Teacup', I used the image of the stern of the Windrush ship as the catalyst for my work. It was my idea to incorporate images of china tea-ware throughout the body of work that unfolded, in order to follow this shape (ship). Interestingly, I think that the shape (ship) almost mimics a tea cup in its structure.

Each piece in the series has its own flavour dealing with different aspects and even different timelines concerning the lives of the original Windrush immigrants and their descendants. Perhaps, one of the strongest elements in the series are the tea bags which I have included in several of the pieces, so far. The teabag to me illustrates, vividly, the essence being drained from the Black man until there's nothing left for him to give. Therefore, making him into a useless person. This theme can be seen, specifically, in two works in the series: 'Tilbury Undertow' and 'The Reusables'. In both instances, I show the physical straining of the tea bag. I think that it is almost like the releasing of blood and tears.

While constructing the paintings, I also keep in mind the atmosphere and mood I want to create. In this series, there is a dark palette with tea stained hues. I use the presence of water in almost all the pieces to represent drowning, or the sinking of truth that may one day resurface. In the series, I've used the recurring symbol of HMT, Her Majesty's Treasury, which can be seen on the tea bags' tags and tea cups. Interestingly, the Treasury office from the inaugural voyage of the HMT Empire Windrush ship was responsible for acquiring and running the vessel till its demise. 
The painting: 'May Day, Man Overboard' (See Alix Pierre's article in Cultural and Pedagogical Inquiry, Vol. 11, No. 3, 2019, pp. 44-45) is perhaps the piece that represents an almost literal interpretation of the lived experiences of the typical Windrush passenger. In the painting, the welldressed man sits on a sofa at the bottom of the ocean, or in the depths of the sullied tea. I have represented him as a living, breathing tea bag that is being drained as he thinks that he is on his way to 'the promised land', in London. This piece illustrates the broken hopes of the Black man. He has worked and even fought valiantly in the World Wars for the British Empire. This notion is also why I chose to include a poppy flower, on the man's chest, representing the West Indian veterans of World War II.

To not leave out the descendants of the Windrush's original generation of immigrants, I created another piece called 'Brixton Brewing' (in this issue). This work remembers the riots that British West Indians created as their responses, in 1981, to England's continuing social and economic inequities, racism and police brutality. Dark smoke billowing out of a tea cup is a dramatic way of representing this idea. 


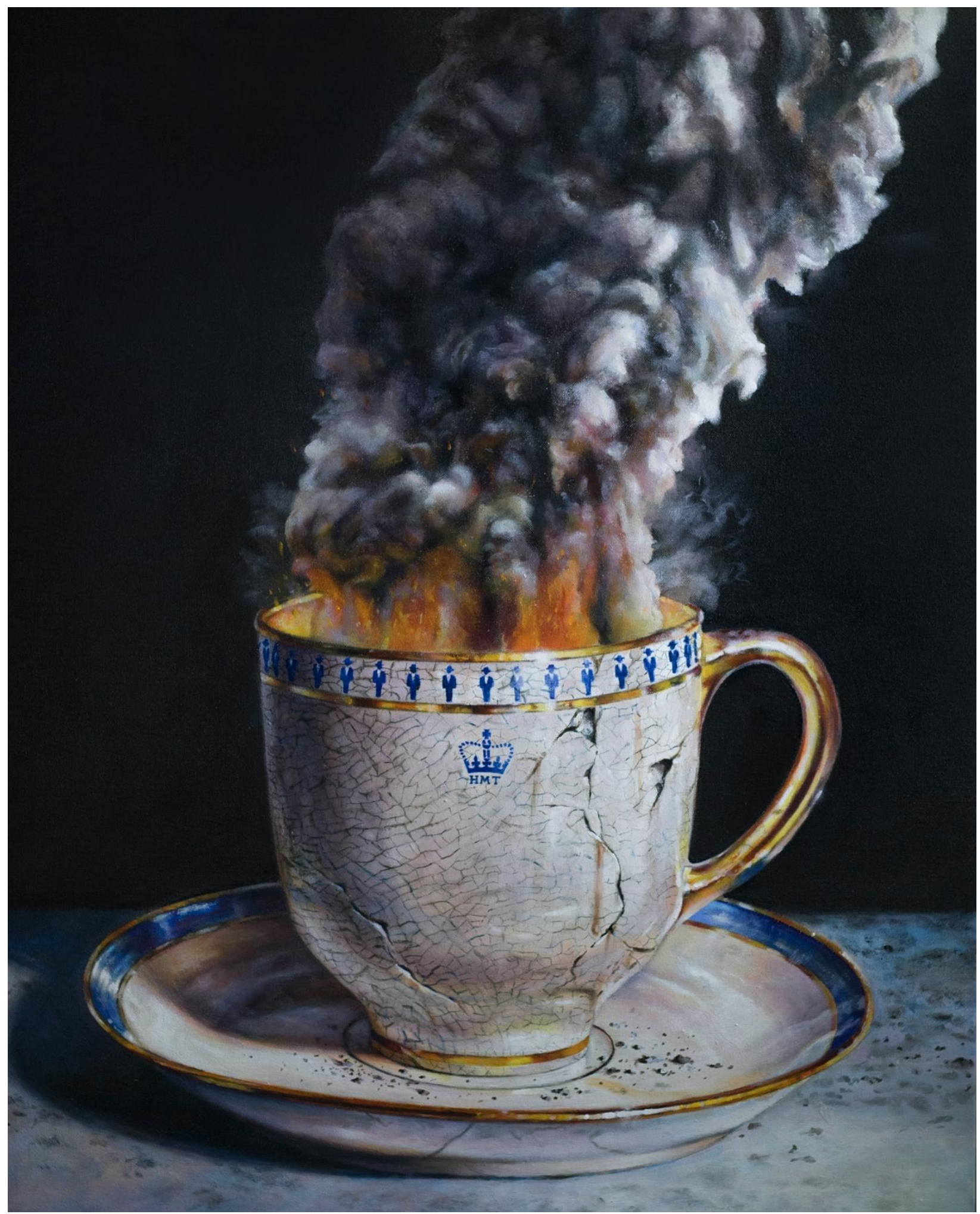

\section{Brixton Brewing}

Acrylic on canvas, 32" x 24", 2018

Cultural and Pedagogical Inquiry, Summer 2020, 12(1), pp. 305-308

ISSN 1916-3460 @ 2020 University of Alberta

http://ejournals.library.ualberta.ca/index.php/cpi/index 


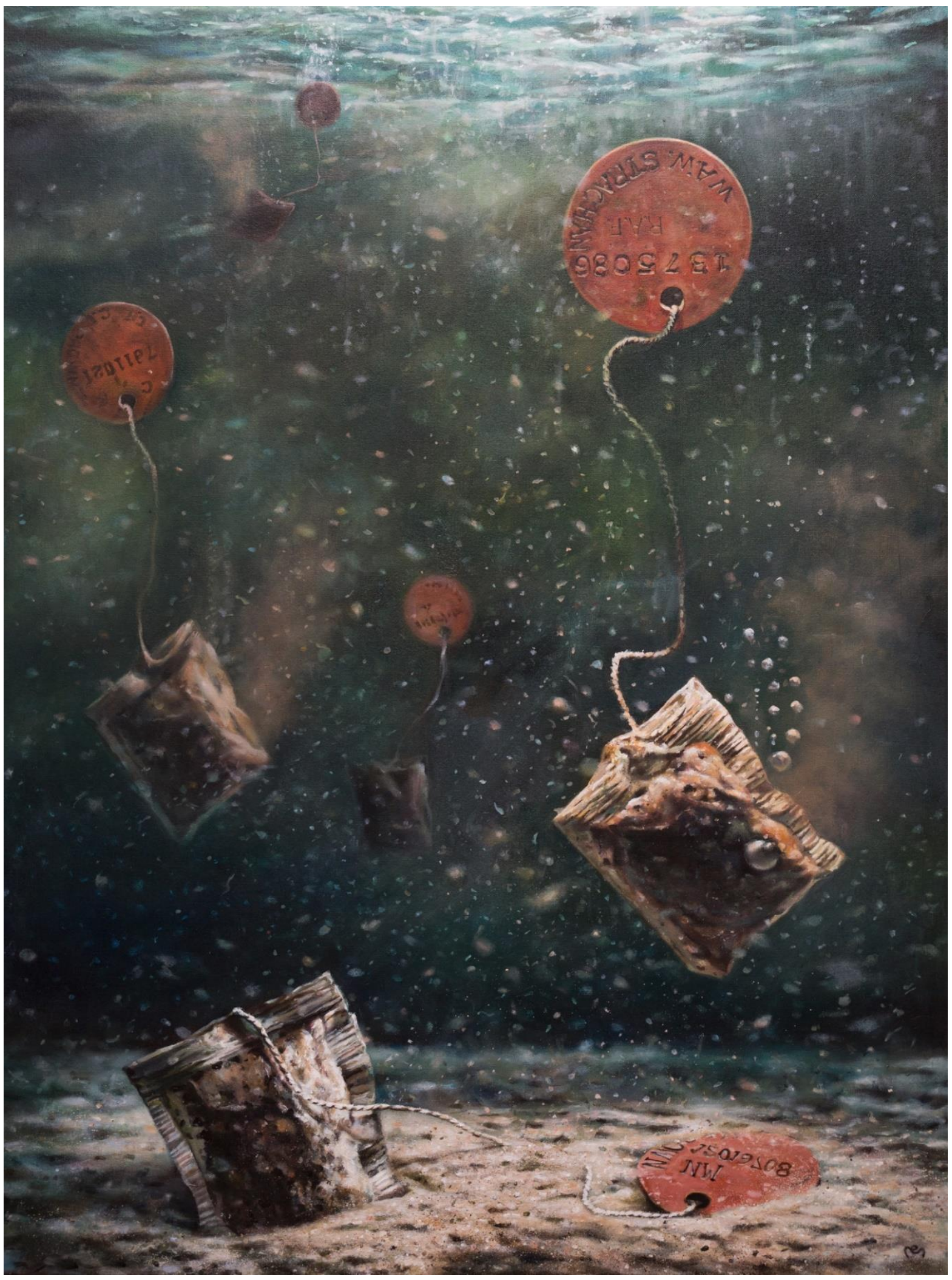

\section{The Drop}

Acrylic on canvas, 40" x 30", 2019

Cultural and Pedagogical Inquiry, Summer 2020, 12(1), pp. 305-308

ISSN 1916-3460 @ 2020 University of Alberta

http://ejournals.library.ualberta.ca/index.php/cpi/index 